\title{
Clinical Profile of Biliary Ascariasis Patients and Their Outcome Following Conservative Treatment in Medicine Units of a Tertiary Level Hospital
}

\author{
Khondaker MFA ${ }^{1}$, Sayeed $\mathrm{MA}^{2}$, Nayeem A ${ }^{3}$, Sardar $\mathrm{MH}^{4}$
}

\begin{abstract}
Background: Ascariasis is one of the most common helminthic infections in the world. Different modalities of treatment are available for biliary ascariasis. The simple conservative treatment has shown high success rate in studies in different countries. Objective: The aim of this study was to see the clinical profile of biliary ascariasis patients and their outcome following initial conservative treatment and on subsequent follow up of a period of four week. Methodology: It was a cross sectional descriptive type of study conducted in the medicine units of Chittagong Medical College Hospital from March 2007 to February 2008. A total of fifty cases with ultrasonographic evidence of round worm in biliary tree with recent onset of pain were included. All cases were initially given a fixed conservative treatment. Patients were kept on observation to note symptomatic improvement. On between 3rd to 5th day of hospitalization repeat abdominal ultrasound in all patients were done. Patients deteriorated clinically and biochemically were sent for ERCP or surgery. Patients, not cleared of worm, were followed up 2 weekly for a period of 4 week. Results: Mean age was 33.12 years. Majority were female (88\%) and most of the female patients (93\%) were of reproductive age group. $13.63 \%$ of female patients were pregnant. $90 \%$ patients came from rural areas. All patients presented with upper abdominal pain. The most common site of entrapment ( $78 \%$ cases) was common bile duct. 47 patients $(94 \%)$ responded with conservative treatment. At the time of discharge (on 3rd -5th day), abdominal ultrasound showed 36 patients (72\%) had evacuated their Ascaris. Further follow up showed disappearance of the parasite in total 42 cases (84\%). Conclusion: Biliary ascariasis predominates classically in middle-aged rural Bangladeshi women. The vast majority of patients can be successfully treated with conservative measures.
\end{abstract}

Key word: Biliary ascariasis, acalculous cholecystitis, pancreatits, ERCP (endoscopic retrograde cholangio pancreatography), duodenoscopy

\section{Introduction}

Ascariasis is one of the most common helminthic infections in the world. The World Health Organization estimates that 1.3 billion people or a quarter of the human race are affected by ascariasis ${ }^{1,2}$. Biliary ascariasis is the most feared and well known complication of intestinal ascariasis. Ascaris lumbricoides (A. lumbricoides), a nematode, is the causative agent of ascariasis and normally lives in the small intestine, but may occasionally enter into the biliary tree from duodenum through ampulla of Vater leading to biliary ascariasis.

Data about morbidity and mortality caused by A. lumbricoides are scarce. In a report from India, the authors stated that ascariasis was similar to gall stones as a causal factor for biliary disease in adults ${ }^{3}$. Other studies report that $10 \%$ of paediatric admission in surgical emergency department is due to hepatobiliary and pancreatic ascariasis ${ }^{4}$ and $11 \%$ of the patients attending the surgical ward for gall-bladder or biliary tree complications are presented with $A$ lumbricoides in the biliary tree ${ }^{5}$. A retrospective study held in 2001 reported that pancreaticobiliary ascariasis is the second most common cause of acute pancreatitis in the Bangladeshi population ${ }^{6}$. Biliary ascariasis causes upper abdominal pain, nausea, vomiting and rarely jaundice. It can give rise to acute complications like acute cholecystitis, acute cholangitis, acute pancreatitis, liver abscess and if the worm persists for long, can give rise to chronic complications like recurrent pyogenic cholangitis, biliary stone, benign biliary stricture and even cholangiocarcinoma $a^{3,7}$. Diagnosis of biliary ascariasis can be reliably done by ultrasound ${ }^{4,10}$. It is also useful in the follow up as it can be performed repeatedly to monitor the spontaneous exit of worms from the bile duct. Different modalities of treatment are available for biliary ascariasis. Surgical extraction of worm was the only method of treatment in the past when endoscopic interventional treatment was not introduced and efficacy of

1. Dr. Mohammad Faiz Ahmad Khondaker, Residential Physician, 250 Bed General Hospital, Noakhali

2. Prof. Dr. Md. Abu Sayeed, Professor, Department of Medicine, Chittagong Medical College Hospital, Chittagong

3. Dr. Abu Nayeem, Resident Physician, Shaheed Suhrawardy Medical College Hospital, Dhaka

4. Dr. Mohammad Hafiz Sardar, Assistant Professor, Department of Medicine, DMCH, Dhaka

Correspondence

Dr. Mohammad Faiz Ahmad Khondaker, Residential Physician, 250 Bed General Hospital, Noakhali; Mobile: 01711571879;

E-mail: faizkhondaker@yahoo.com 
conservative treatment was not extensively studied. Different studies done after 1990 showed that more than $90 \%$ of patients of biliary ascariasis improved by simple conservative treatment ${ }^{3,7,11}$. True success in term of complete disappearance of Ascaris from biliary tree was achieved in $97 \%$ of adult cases with conservative treatment and sequential ultrasound follow up in a study done on 69 patients $^{12}$. Worm can also be extracted by ERCP with or without sphincterotomy and by surgical exploration of bile duct. In some cases it can be done by simple duodenoscopy if a part of worm is seen at ampulla ${ }^{7,11}$. However, ERCP is technically demanding procedure and expensive, not easily available in every centre and not devoid of complications. Therefore it is now restricted to patients who fail to respond to conservative treatment ${ }^{3,7,8,12}$. In Bangladesh, the standard of living of majority of people is low which contribute to the spread of Ascaris infestation and biliary ascariasis. The district hospitals and even the tertiary hospitals of this country are not provided with ERCP facilities. So the simple conservative treatment that has shown high success rate in studies in different countries including India might be more appropriate option for biliary ascariasis management in this country. A very few studies have been done to see the success rate with conservative measures among the population so far. The aim of this study was to see the clinical profile of biliary ascariasis patients and their outcomes following initial conservative treatment and on subsequent follow up of a period of four week.

\section{Methodology}

This cross sectional descriptive type of study was carried out in the Department of Medicine at Chittagong Medical College Hospital (CMCH) from March 2007 to February 2008. A total of 50 cases who got admitted with ultrasonographic evidence of round worm in any part of biliary tree like common bile duct, gall-bladder or intrahepatic biliary tree with pain were included in this study. Patients with confusing ultrasonogram report, incidental diagnosis of biliary ascariasis with no pain, concomitant biliary stone disease and debilitated patient with comorbid diseases were excluded from the study. After enrolment of every patient in this series a thorough history regarding patient's particulars, socioeconomic and personal history, presenting complaints, past history of passing worm in stool or vomitus, recurrent abdominal pain and history of any biliary surgery or procedure like ERCP were obtained to have features in favour of biliary ascariasis. Careful physical examination was done in every case. Complete blood count, serum bilirubin, serum alkaline phosphatase and serum amylase estimation were done. All cases were initially given a fixed conservative treatment consisting of nothing per oral, nasogastric suction, intravenous fluids, intravenous anti-spasmodic (tiemonium methyl sulfate), intravenous antibiotic (if features of cholangitis) and oral anti helminthic (Syrup Pyrantel Pamoate $10 \mathrm{mg} / \mathrm{kg}$ per oral stat). Patients were kept on observation to note symptomatic improvement in term of subsidence of pain and tenderness. Persisting pain more than 24 hours or patient with high amylase $(>600 \mathrm{IU} / \mathrm{L})$ was sent for duodenoscopy with an attempt of endoscopic removal of worm if visible at the ampulla of Vater. On between 3rd to 5 th day of hospitalization repeat abdominal ultrasound in all patients. Patients deteriorated clinically and biochemically were advised for ERCP or surgery. Patients, who were not cleared of worm, were advised to come 2 weekly for a period of 4 week. During follow up clinical assessment and persistence or disappearance of worm was evaluated by USG. All patients were advised to take anthelmintic drug at every 2-3 months interval. All the information of particular case was recorded in a predesigned case record form and finally all the relevant data was processed and analyzed by SPSS software version 17 .

\section{Results}

As the study was conducted in adult medicine wards, all cases were above 13 years. A 21(42\%) cases were of 31-40 years age group. Mean \pm SD age was $33.12 \pm 6.8$ years. Female patients were predominant than male which were

Table 1: Ultrasonographic findings of the patients $(n=50)$

\begin{tabular}{lccc}
\hline $\begin{array}{l}\text { Site of worm } \\
\text { entrapment }\end{array}$ & No. of Worm & $\begin{array}{c}\text { No. of } \\
\text { patients }\end{array}$ & Total (\%) \\
\hline $\begin{array}{l}\text { Common bile } \\
\text { duct }\end{array}$ & Single & 32 & $39(78 \%)$ \\
& $\begin{array}{c}\text { Two } \\
\text { Two/bolus }\end{array}$ & 4 & \\
Gall bladder & Single & 3 & $3(6 \%)$ \\
& More & 0 & \\
Right hepatic & Single & 3 & $3(6 \%)$ \\
duct & More & 0 & \\
$\begin{array}{l}\text { Both right and } \\
\text { left hepatic }\end{array}$ & Single & 2 & $2(4 \%)$ \\
duct & More & 0 & \\
$\begin{array}{l}\text { Both extra } \\
\text { hepatic \& intra } \\
\text { hepatic biliary }\end{array}$ & Single & 0 & $3(6 \%)$ \\
tree & More & 3 & \\
\hline
\end{tabular}

$44(88 \%)$ cases and $6(12 \%)$ cases respectively. Most of the female patients were of reproductive age group (13-50 years) and the number was 41 out of $44(93 \%)$. A $13.6 \%$ of female patients were pregnant. Of them, 5 cases had

Table 2: Time needed for improvement with conservative treatment. $(n=47)$

\begin{tabular}{lcc}
\hline Time Period & No. of Patients & Percentage \\
\hline O-24 hrs & 8 & $16 \%$ \\
$25-48 \mathrm{hrs}$ & 17 & $34 \%$ \\
$49-72 \mathrm{hrs}$ & 9 & $18 \%$ \\
$73-96 \mathrm{hrs}$ & 10 & $20 \%$ \\
$97-120 \mathrm{hrs}$ & 3 & $6 \%$ \\
Total & $\mathbf{4 7}$ & $\mathbf{9 4 \%}$ \\
\hline
\end{tabular}


pregnancy of more than 20 weeks and $45(90 \%)$ patients came from rural areas and only $5(10 \%)$ from urban areas (Fig. 1). All patients in this study presented with upper abdominal pain. Associated nausea and/or vomiting were also an important complaint and $37(74 \%)$ patients had this. A total of $12(24 \%)$ patients had history of passage of

Table 3 : Presence of Ascaris in biliary tree in sequential ultrasounds

\begin{tabular}{lccc}
\hline Localization & Entry & $\mathbf{3}^{\text {rd }}-\mathbf{5}^{\text {th }}$ day & $\begin{array}{c}\text { Sequential } \\
\text { follow up }\end{array}$ \\
\hline CBD & 39 & 8 & 4 \\
Gall-bladder & 3 & 0 & 0 \\
$\begin{array}{l}\text { Intrahepatic } \\
\text { biliary tree }\end{array}$ & 3 & 1 & 0 \\
$\begin{array}{l}\text { Both } \\
\text { extrahepatic \& }\end{array}$ & 5 & 5 & 4 \\
$\begin{array}{l}\text { intrahepatic } \\
\text { biliary tree }\end{array}$ & & & \\
Total & $\mathbf{5 0}$ & $\mathbf{1 4}$ & $\mathbf{8}$ \\
\hline
\end{tabular}

worm with vomiting and $7(14 \%)$ patients had seen worm in their stool and $12(24 \%)$ patients had history of recurrent upper abdominal pain and $4(8 \%)$ cases of them was diagnosed as biliary ascariasis by ultrasound. Sonographic profile of Ascaris showed the most common site of entrapment was common bile duct (78\% cases). Worm was visualized in gall-bladder in $6 \%$ cases. Worm occupying in both extrahepatic and intrahepatic biliary tree was seen in $6 \%$ cases. In most cases $(80 \%)$ the number of worm was single (Table 1). Complications were observed in $22(44 \%)$ cases only. Acute acalculous cholecystitis was the most common complication found in $7(14 \%)$ cases while cholangitis and acute pancreatitis was observed in $6(12 \%)$ and $5(10 \%)$ cases respectively. 47 (94\%) patients responded with conservative treatment and the highest number of patients (34\%) needed 25-48 hours to respond (Table 2).

Table 4 : Outcome of different modalities of treatment

\begin{tabular}{cccc}
\hline Modalities $\begin{array}{c}\text { of } \\
\text { treatment }\end{array}$ & $\begin{array}{c}\text { No of } \\
\text { Patient }\end{array}$ & \multicolumn{2}{c}{ Out come } \\
\cline { 3 - 4 } & & $\begin{array}{c}\text { Symptomatic } \\
\text { improvement }\end{array}$ & $\begin{array}{c}\text { Ascaris } \\
\text { Clearance }\end{array}$ \\
\hline Conservative & 50 & $47(94 \%)$ & $42(84 \%)$ \\
ERCP & 4 & $4(100 \%)$ & $4(100 \%)$ \\
Surgery & 1 & $1(100 \%)$ & $1(100 \%)$ \\
\hline
\end{tabular}

Duodenoscopy was done in 15 patients $(30 \%)$ and in only 4 patients (8\%) worm was seen at ampulla of Vater and in 3 of them worm could be extracted by dormia basket. In 1 case worm could not be extracted as it managed to migrate fully in the $\mathrm{CBD}$ during the procedure. At the time of discharge (on 3rd -5th day), abdominal ultrasound showed presence of Ascaris in 14 of the 50 patients; that is 36 (72\%) patients had evacuated their Ascaris. Further follow up showed disappearance of the parasite in 42 (84\%) cases.
In rest $8(16 \%)$ cases parasites persisted in the CBD (4 cases) and in both extrahapatic and intrahepatic biliary tree (4 cases) (Table 3). All the 50 patients were given conservative therapy as initial treatment. A total of 47 patients $(94 \%)$ improved symptomatically with that treatment. On sequential ultrasonic follow up, 42(84\%) of them are found to show success in achieving Ascaris clearance from the biliary tree without any invasive procedure. ERCP was done in 4 cases $(8 \%)$ and surgery in one case $(2 \%)$. Both ERCP and surgery showed $100 \%$ success in achieving symptomatic improvement as well as Ascaris clearance (Table 4).

Fig. 1: Distribution of patients with residence $(n=50)$

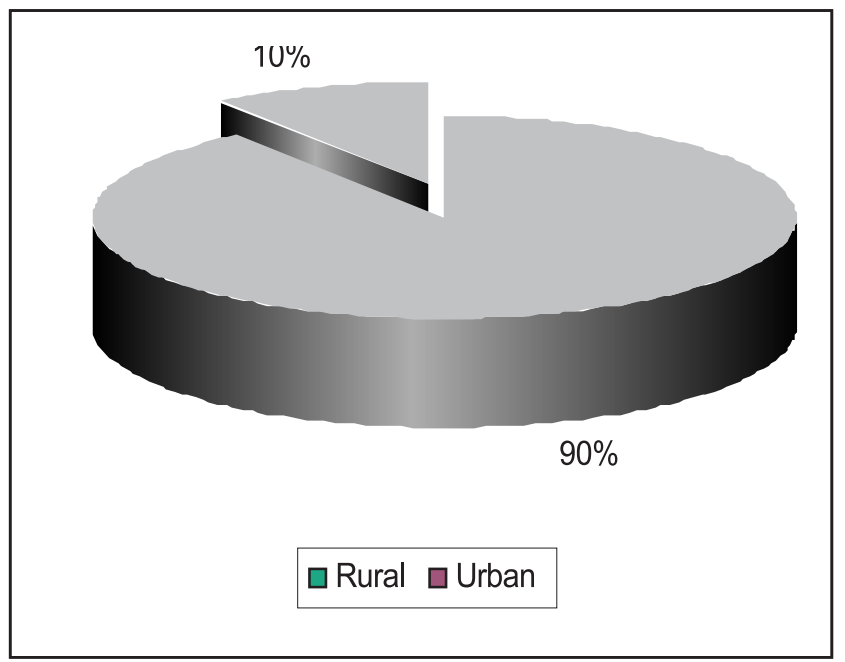

\section{Discussion}

In this study most of the patients $(42 \%)$ were in age group of 31-40 years (3rd decade) and the mean age was $33.12 \pm$ 6.8 years. This is consistent with studies done by Islam ${ }^{22}$ and $\mathrm{Kaisar}^{23}$. In majority of the studies in adult patients, mean age is in third decade; probably it is due to more outdoor activities of young people. The incidence of biliary ascariasis was more common in middle aged female than it is in male. In this study, $44(88 \%)$ cases were female and only $6(12 \%)$ cases were male. Almost same gender discrimination is seen in all studies done home and abroad $^{3,11,12,22,23}$. It is possible that in these young females, the hormone progesterone leads to relaxation of the smooth muscle of the sphincter of Oddi allowing the Ascaris to gain easy entrance to the biliary duct. Among the 44 female patients in the study, 6(12\%) patients were pregnant. Progesterone level is very high during pregnancy causing sphincter of Oddi more relaxed ${ }^{26}$.

In this study the most frequent presenting symptom was upper abdominal pain which was present in all the patients. This is the single most frequent complaint in almost all series of study $3,7,12,22,23$. Vomiting, fever with or without chills and rigor and jaundice are inconstant variable features of biliary ascariasis that depends upon degree and 
extent of bile duct inflammation and systemic insult. Ali ${ }^{24}$ states that emesis of worm is highly suggestive of biliary ascariasis in a symptomatic patient, but unfortunately it is absent in majority of cases. In this study, 12(24\%) patients had history of passing worm through vomitus during biliary colic. Passing of round worm with stool is an indicator of this worm infestation. However, in the context of biliary ascariasis, positive history reinforces the suspicion. In this study $7(14 \%)$ patients had reported of passing worm in stool. Ultrasound is a non-invasive, safe, cheap and reliable diagnostic tool for the diagnosis of biliary ascariasis ${ }^{4,10}$. Therefore the main criteria for defining the case of this study were presence of worm in biliary tree proved by ultrasonogram. Kamrul ${ }^{25}$ in his study found round worm within common bile duct (CBD) in 93.3\% cases, within gall-bladder in $3.3 \%$ cases, within common hepatic duct in $3.3 \%$ cases. Gonzalez et al ${ }^{12}$ reported Ascaris in CBD in $81.1 \%$ cases, in gall bladder $10.1 \%$ cases and in the intra hepatic biliary tree in $8.6 \%$ individuals. Present study revealed almost same ratio regarding site of entrapment-CBD in $78 \%$ cases, gall bladder in $6 \%$ cases, extra hepatic biliary tree in $10 \%$ cases and both extra hepatic and intra hepatic biliary tree in $6 \%$ cases.

In the present study more than two or bolus of worms were found in $12 \%$ cases only. And most of these patients developed complications, response with conservative treatment was slow or not at all and most required invasive procedure for improvement. In most of the studies $3,8,12,22,23$ the common site of entrapment was common bile duct and the usual number of worm was single. In this study it was found an acute acalculus cholecystitis in 14\% cases and cholangitis in $12 \%$ and 2 patients who had history of recurrent abdominal pain developed septic shock. Recurrent pyogenic cholangitis might be responsible for this fatal complication. Acute pancreatitis occurs in 4-36\% of patients with pancreatico-biliary ascariasis ${ }^{7,8}$ and most of the mortality associated with biliary ascariasis has been attributed to acute pancreatitis ${ }^{7}$. In the other hand $10 \%$ of the patients had acute pancreatitis of mild form, all with favourable evolution. Obstructive jaundice developed in $4 \%$ cases only. Kamrul ${ }^{25}$ in his study documented obstructive jaundice in $3.3 \%$ cases. There were no complications in $56 \%$ cases of this study. All the patients in this study were initially given conservative treatment. In most of the studies same regimen was applied as initial therapy. Half of the patients $(50 \%)$ showed improvement within 48 hours with the initial conservative treatment and 94\% patients improved within 96 hours. This observation coincides with that of most studies done in India and other endemic countries ${ }^{7,8,12}$. In a study carried out by Gonzalez et al12 duodenoscopy was done in $30(42 \%)$ out of 69 cases who had persistent symptoms and high amylasemia; in $14.4 \%$ a worm was found at ampulla of Vater and extracted by traction applied to the extra ampullary portion without sphincterotomy. In this study patients who fulfilled the same criteria were $15(30 \%)$ in number and underwent duodenoscopy. In 4 cases worm was seen at ampulla and successful worm extraction had been possible in 3(6\%) of them providing immediate relief of symptoms.

Repeat ultrasonogram done on 3rd to 5th day showed that worm was present in 14 patients, that is, 36(72\%) patients had evacuated their Ascaris. This figure was $81.1 \%$ in the series of Gonzalez et al ${ }^{12}$. Among the 14 patients with persistence of worm, ERCP was done in 3 cases on emergency basis as their conditions had deteriorated clinically and biochemically. Rest of the 11 patients was discharged with advice to come after 2 weeks for follow up. One patient came with features of obstructive jaundice with grossly dilated CBD and bolus of worm within it and one patient came with features of cholangitis and persistence of worm in biliary tree after 2 weeks. The first patient was referred to surgery for exploration and second one was advised for ERCP. Among the remaining 9 patients- 3 patients were found to have cleared of worm at follow up on 2 nd week, 3 patients were cleared of worm at follow up after another 2 week and 3 remained asymptomatic with persistence of worm. Previous studies have shown that $42-97 \%$ of patients could be treated by non-invasive means. The highest $97 \%$ success in terms of Ascaris clearance was achieved without any invasive procedure and it was documented on sequential ultrasound in a period of 6 months ${ }^{12}$. In this study patients were followed up for 4 weeks and achieved $84 \%$ Ascaris clearance with conservative measures and was found a higher success rate which was achieved if the patients could be kept on follow up for longer period.

ERCP was done in $4(8 \%)$ cases $(8 \%$ ) in our study- in 3 cases as they failed to respond to conservative therapy and in 1 case due to recurrence of symptoms after 2 week. Along with live worm, dead worm and debris were extracted in the first 3 cases. These particular 3 cases were complicated with severe cholangitis and sepsis and had history of recurrent upper abdominal pain and previous attack of biliary ascariasis. Persistence of worm and debris from previous attacks has caused their failure to respond to initial therapy. ERCP was successful in all 4 cases. Surgical removal of worm was done in one case (2\%) and post operative period was uneventful. Khuroo et al19 showed that ERCP was required in $29 \%$ of patients after failing conservative management which was much higher than was required in the present study and several other studies $12,22,23$. Most authors have reported successful worm extraction rates in excess of $90 \% 21$. In this study worm extraction could be possible in all four cases (100\%) with no complication.

\section{Conclusion}

Biliary ascariasis predominates classically in middle-aged rural Bangladeshi women. The usual presentation is upper abdominal pain associated with nausea and vomiting. A significant number of patients develop some acute 
complications that sometimes can be fatal. The vast majority of biliary ascariasis patients can be successfully treated with conservative measures and it should be the initial and principal mode of treatment. Patients showing symptomatic improvement but retaining worm in biliary tree should be kept on follow up. Nationwide study to detect the incidence and complication of biliary ascariasis can be conducted to know the magnitude of this health problem.

\section{References}

1. Gabaldon A, Mofid C, Morishta K, Moskovski S, Sankale M, Standen DD. Control of ascariasis (report of WHO committee). World Health Organ Tech Rep Ser 1967:379:1-39

2. Crompton DW, Nesheim MC, Pawlowski ZS, editors. Ascariasis and its prevention and control. Taylor and Francis: London; 1989

3. Khuroo MS, Zargar SA. Biliary ascariasis: A common cause of biliary and pancreatic disease in an endemic area. Gastroenterology 1985;88:418-23

4. Khuroo MS, Zargar SA, Mahajan R, Bhat RL, Javid G. Sonographic appearances in biliary ascariasis. Gastroenterology 1987;93:267-72

5. Kamiya T, Morishita T, Peredo R, et al. Duodenoscopic management in biliary ascariasis. Dig Endose 1993;5:179-82

6. Uddoula MS, Miah MAR, Rahman M, Roy PK, Hasan M. Study of aetiological factors and mode of clinical presentation of acute pancreatitis in the Bangladeshi population. BMJ 2005;34(1):17-21

7. Khuroo MS, Zargar SA, Mahajan R Hepatobiliary and pancreatic ascariasis in India. Lancet 1990;335:1503-6

8. Lim KG, Sellaiah SP. Biliary ascariasis and extrahepatic cholangiocarinoma: A report of two cases Singapore Med J 1994;35:400-2

9. Flavell DJ. Liver-Fluke infection as an aetiologic factor in the bileduct carcinoma of man. Trans R Soc Trop Med Hyg 1981;75:814-24

10. Kamath PS, Joseph DC, Chandran R, Rao SR, Prakash ML, D'Cruz AJ. Biliary ascariasis: Ultrasonography, endoscopic retrograde cholangiopancreatography and biliary drainage. Gastroenterology 1986;91:730-2

11. Khuroo MS Zargar SA, Yattoo GN, Javid G, Dar MY, Boda Ml, et al. Worm extraction and biliary drainage in hepatobiliary and pancreatic ascariasis. Gastrointest Endosc 1993;39:680-5

12. Gonzalez AH, Regaldo VC, Van den Ende JV. Non-invasive management of Ascaris lumbricoides biliary tract migration: A prospective study in 69 patients from Ecuador, Trop Med Int Health 2001;6:146-50

13. Khuroo MS, Zargar SA, Yattoo GN, Koul B, Khan BA, Dar MY, et al. Ascaris-induced acute pancreatitis. Am J Surg 1992;79:1335-8

14. EI-Sheikh MAR. Al-Karawi MA, Yasawy MI. Modern techniques in the diagnosis and treatment of gastrointestinal and biliary tree parasites. Hepatogastroenterology 1991;38:180-8

15. Cobo A, Hall RC, Torres E, Cuello CJ. Intrahepatic calculi. Arch Surg 1964; 89:936-41.

16. Schulman A. Intrahepatic biliary stones: Imaging features and a possible relationship with Ascaris lumbricoides. Clin Radiol 1993;47:325-32

17. Choi Tk. Wong J. Severe pancreatitis caused by parasites in the common bile duct. J Trop Med Hyg 1984;87:211-4

18. Chen YS, Den BX, Huang Bl, Xu LZ. Endoscopic diagnosis and management of Ascaris induced acute pancreatitis. Endoscopy 1986;181:27-8

19. Javid G, Wani NA, Gulzar GM, Khan BA, Shah AH, Shah OJ et al. Ascaris induced liver abscess. World J Surg 1999;23:1191-4

20. Pawloski ZS. Ascariasis. In: Warren KS, Mahmoud AA, editors. Tropical and Geographical Medicine. 2nd ed. McGraw Hill:USA;1995. P.369-78
21. Khuroo MS. Ascariasis. Gastroenterol Clin North Am 1996;25:553-77.

22. Islam MR. Biliary ascariasis- a study of 50 cases. Dhaka: Bangabandhu Sheikh Mujib Medical University, 2001. [FCPS Dissertation], BCPS library

23. Kaisar MS. Varied Presentation of Biliary ascariasis with its consequences in a regional hospital- study of 50 cases. Barishal, Bangladesh: Sher-E-Bangla Medical Hospital,2006. [FCPS Dissertation], BCPS library

24. Ali A. Review of management of biliary ascariasis. JCMCTA 2003;14(2):29-38

25. Kamrul HM. Ascariasis- its biliary complications and presentationstudy of 30 cases. [FCPS Dissertation], BCPS library

26. Cohen S. The sluggish gallbladder of pregnancy. N Eng J Med. 1980; 302: $397-398$ 